\section{A Graphical Control Chart for Monitoring Leaf count of Easter Lily to Support Crop Timing Decisions}

\author{
P.R. Fisher and R.D. Heins
}

Additional index words. technology transfer, leaf unfolding rate, graphical tracking, process control

Summary. A graphical control chart was developed to monitor leaf count of Easter lily (Lilium longiflorum Thunb.) and make temperature recommendations based on predictions of a leaf unfolding rate (LUR) model. The graph allows observed and target leaf count to be compared visually over time. Timing of the visible bud stage, when flower buds are visible externally on the plant, is important to time flowering for the Easter sales period. The optimum LUR and average daily temperature required to achieve a target visible bud date can be read directly from the chart. The approach provides an intuitive method for transferring quantitative models to growers.

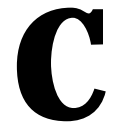

ontrol of development rate is critical for Easter lily because there is a narrow market period: Easter falls on a different date every year, and plant development varies depending on the field conditions under which bulbs were grown. Precise control of development rate therefore can be achieved by manipulating greenhouse temperature.

The objective of this project was to develop a graphical control chart

\footnotetext{
${ }^{1}$ Department of Horticulture, Michigan State University, East Lansing, MI 48824-1325.

We thank University Outreach at Michigan State University for providing funding for this project and $J$. Heinrich Lieth at the University of California (Davis) and Niels Ehler at the Royal Veterinary and Agricultural University in Copenhagen, Denmark, for their cooperation. The cost of publishing this paper was defrayed in part by the payment of page charges. Under postal regulations, this paper therefore must be hereby marked advertisement solely to indicate this fact.
}

that provides decision support pertaining to the optimum greenhouse temperature based on leaf unfolding rate (LUR) of Easter lily. Karlsson et al. (1988) modeled the response of Easter lily LUR to average daily temperature (ADT); a leaf was defined as unfolded when the leaf tip was oriented $45^{\circ}$ from the plant stem, and LUR was the rate of increase in leaf count per day. From 15 to $22 \mathrm{C}$, LUR was approximately a linear function of average temperature, allowing computation of the ADT required to achieve a desired LUR

$\mathrm{ADT}=\mathrm{LUR} \times 10.64+1.12$

For research-based models to be adopted by end-users, technologies that package complex quantitative information into intuitive formats are needed. One technique developed for Easter lily, poinsettia, and chrysanthemum height control is the graphical tracking of plant height over time, in which actual plant performance is compared with a target curve (Heins et al., 1987; Karlsson and Heins, 1994). We developed a similar tool for LUR, where predictions from Eq. [1] are summarized on a control chart (Fig. 1).

In commercial Easter lily production, crops are scheduled to reach visible bud (VB) 30 to 35 days before shipping, because at 17 to $20 \mathrm{C}$ lilies require 30 to 35 days from $\mathrm{VB}$ to anthesis (Erwin and Heins, 1990). At $\mathrm{VB}$, flower buds are visible on $50 \%$ of the crop without removing leaves, and this stage provides an intermediate milestone to keep crop timing on schedule. In the example crop (Fig. 1), 50 plants were grown at Michigan State Univ., with a target flower date of 1 Apr. 1995 and a target VB of 1 Mar.

After 20 leaves unfold, about 2 weeks after plants emerge, growers begin regular plant dissections to check for flower bud initiation, which is the first observable presence of flower bud primordia (Wilkins and Roberts, 1969). The number of leaves on a plant can be counted on the day of flower bud initiation to estimate the total number of leaves yet to unfold. The average number of unfolded leaves at initiation and the estimated final leaf number at VB can be plotted on the LUR control chart. At VB, all but about five leaves have unfolded (Fisher et al., 1995). The number of leaves that unfolds between initiation and 
$\mathrm{VB}$ is the total number of leaves not unfolded at initiation minus five leaves.

Initiation in the example crop (Fig. 1) occurred on 21 Jan., at which time an average of 27 leaves had unfolded and an estimated total of 98 leaves was present, including unfolded and immature leaves. An estimated average of $66(98-27$ leaves at initiation - 5 remaining leaves) leaves therefore remained to unfold in the 39 days between initiation and VB.

A straight line (Fig. 1) from the number of leaves at initiation to the estimated leaf count at VB (left y-axis) represents a target to compare against actual leaf number. The actual leaf number is written on the left side of the LUR

Fig. 1. An example leaf count graphical control chart. The solid line represents the target leaf count between initiation and visible bud (VB), O = observed leaf count (average of five plants), $=$ recommended greenhouse temperature control setting rounded to the nearest ${ }^{\circ} \mathrm{C}$ using Eq. [1]. control chart, working down from the total leaf number minus five leaves at the top of the $y$-axis. The date is written on the bottom of the control chart, working back from VB to initiation.

The optimum LUR is calculated by optimum LUR = leaves still to unfold by $\mathrm{VB} /$ days to $\mathrm{VB}$

which, in Fig. 1, is 66 leaves/39 days $=1.7$ leaves/day. The target line shows the average LUR needed from initiation to $\mathrm{VB}$ and the desired average temperature (19C using Eq. [1]) to achieve this LUR. Working back along the diagonal dotted lines toward the bottom left, the required LUR and temperature can be read from the chart.

After initiation, unfolded leaves can be counted regularly. In the example crop, the number of unfolded leaves was counted on a sample of five randomly selected plants three times per week. The average leaf count was plotted for each measurement date.

Warm weather, changes in light

\section{Days relative to visible bud}
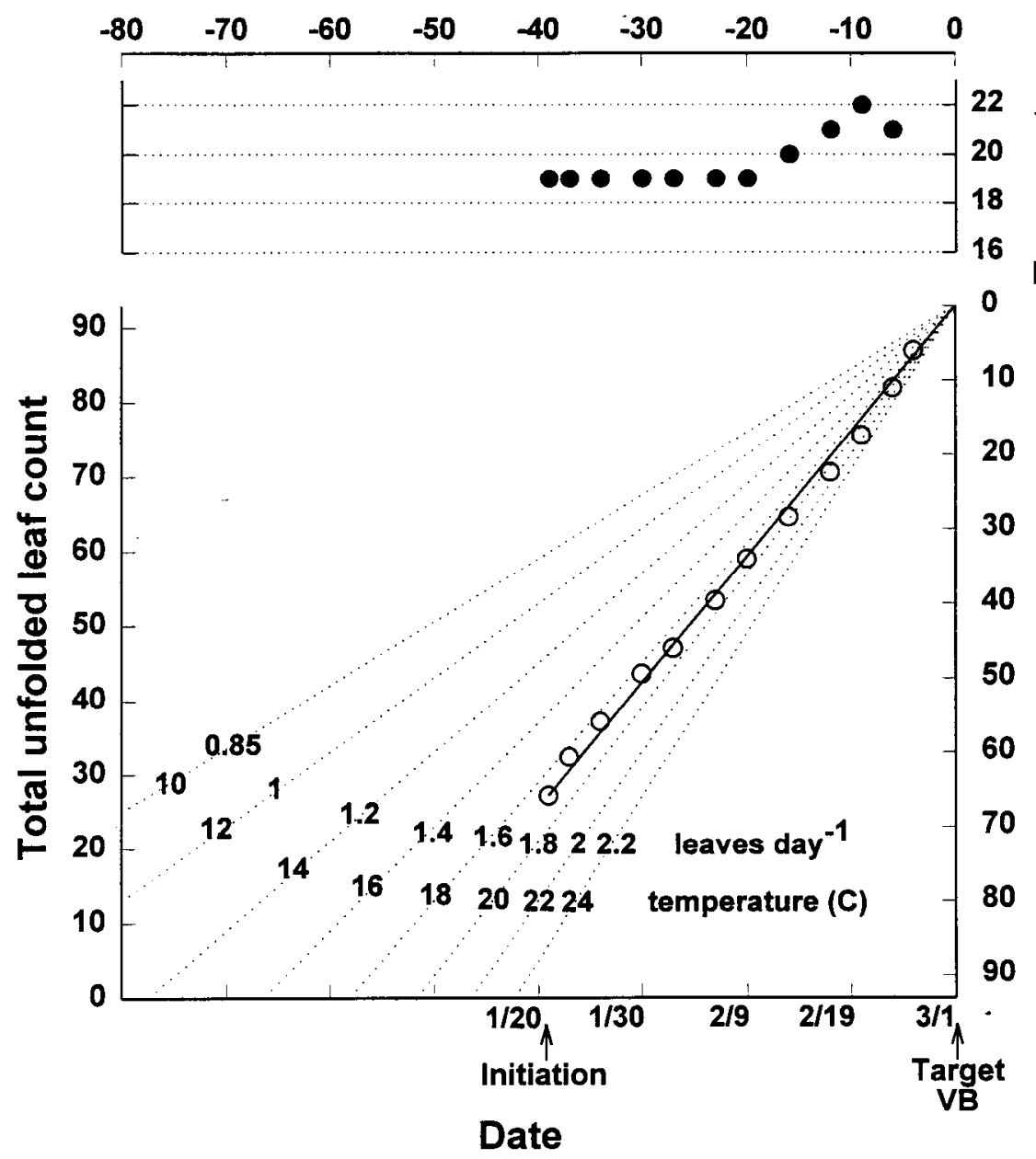

conditions, or some other factor may cause the actual leaf number to deviate from the target, even if the greenhouse temperature control setting is at the required. average temperature (e.g., 19C). If actual leaf count is below the target curve, higher temperatures are needed to increase LUR Conversely, if actual leaf count is above the curve, the temperature can be dropped to reduce LUR The required LUR and temperature can be read from the bottom left of the chart, based on where the measurement point lies with respect to the diagonal dotted lines. In the example crop (Fig. 1), observed leaf count remained near the target curve, and greenhouse temperature settings initially were maintained at 19C. During the 20 days before target VB, observed leaf count was below the curve, and temperature settings were raised to increase LUR For example, greenhouse temperature was set at $21 \mathrm{C}$ on 17 Feb. to achieve a LUR of 1.85 leaves/day.

As the crop approaches the last week before $\mathrm{VB}$, recommendations from the control chart must be treated with caution because slight errors in leaf counting can cause large temperature recommendation errors. Outputs from the LUR model (Eq. [1]) and a model of development rate from VB to flower (Erwin and Heins, 1990) can be averaged during the 10 days before VB to reduce errors from the LUR model.

The actual leaf count at VB in the example crop was 88 leaves, rather than the estimated 93 leaves, and actual VB therefore occurred on 25 Feb., 4 days earlier than the target VB. The 34 days from actual VB on 25 Feb. to the target anthesis date (1 Apr.) was within the range of 30 to 35 days that is acceptable for commercial production, and the crop achieved the final target of $50 \%$ of plants at anthesis on 1 Apr. However, the overestimation of leaf count at initiation indicates that a second plant dissection 15 days before VB would improve accuracy of the leaf count estimate, and the control chart could be recalibrated.

Many Easter lily growers already were using the LUR model (Eq. [1]) to quantify the optimum temperature using a look-up table or a calculator before the LUR control chart was developed. We have had positive responses from growers testing the LUR control chart during 1994 and 1995 
production seasons because it provides the required decision making information in a visual format that clearly displays trends over time.

The approach can be generalized to allow application to other horticultural problem areas in which a process variable, for example, leaf count, flower bud size, or fruit size, is monitored over time. For this method to be applicable, it would be necessary to 1) quantify a final target value of the process variable at a specified date, 2) quantify the response of this process variable to some input, for example, light or temperature, that preferably can be manipulated, and 3) monitor and quantify the process variable over time.

In conclusion, a graphical control chart allows observed and target leaf count to be compared visually over time. To target a specific sales period like Easter, timing of the VB stage is imperative. The optimum LUR and ADT required to achieve the target date can be read directly from the chart. Such an approach provides an intuitive method for transferring quantitative models to growers.

\section{Literature Cited}

Erwin, J.E. and R.D. Heins. 1990. Temperature effects on lily development rate and morphology from the visible bud stage until anthesis. J. Amer. Soc. Hort. Sci. 115:644-646.

Fisher, P.R., R.D. Heins, N. Ehler, J.H. Lieth, M. Brogaard, and P. Karlsen. 1995. A decision-support system for real-time management of Easter lily (Lilium longiflorum Thunb.) scheduling and height: II. Validation. Agr. Systems (In press.)

Heins, R.D., J.E. Erwin, M.G. Karlsson, R.D. Berghage, W.H. Carlson, and J. Biernbaum. 1987. Tracking Easter lily height with graphs: Easter lily response to temperature during forcing. GrowerTalks 51(8):64-65.

Karlsson, M.G., R.D. Heins, and J.E. Erwin. 1988. Quantifying temperature-controlled leaf unfolding rates in 'Nellie White' Easter lily. J. Amer. Soc. Hort. Sci. 113:70-74.

Karlsson, M.G. and R.D. Heins. 1994. A model of chrysanthemum stem elongation. J. Amer. Soc. Hort. Sci. 119:403407.

Wilkins, H.F. and A.N. Roberts. 1969. Leaf counting-A new concept in timing Easter lilies. Minnesota State Florists' Bul. 12:1013. 